INT. J. REMOTE SENSING, 2001, VOL. 22, NO. 14, 2847-2852

\title{
Observations of concentric ring clouds west of Australia
}

\author{
A. J. PRATA, P. G. BAINES \\ CSIRO Atmospheric Research, PMB 1, Aspendale, Victoria 3195, Australia \\ and P. C. TILDESLEY \\ CSIRO Marine Research, GPO Box 1538, Hobart, Tasmania 7001, Australia
}

(Received 24 August 2000; in final form 22 February 2001)

\begin{abstract}
Some interesting cloud formations off the west coast of Western Australia on NOAA AVHRR and GMS-5 images are described. The cloud structures shown here are rare and may be related to the 'Morning Glory' phenomenon. This Letter provides an observational study of these clouds which we are calling 'Concentric Ring Clouds'. A plausible mechanism for their generation is presented in terms of anomalous latent heat release, thunderstom downdraught and outflow causing wave propagation in a low-level wave guide.
\end{abstract}

\section{The observations}

The clouds of interest were observed in AVHRR-2 imagery off the western coast of Australia on two consecutive days in February, 1996. Figure 1 shows a sequence of four thermal infrared images obtained from the AVHRR-2's on 14 and 15 February 1996. There are unusual cloud formations (arcs or parts of 'rings') extending westwards from the coastal region into the ocean in the evening images, and no such clouds in the morning images.

The second image in the sequence shown in figure 1 is re-displayed in figure $2(a)$. This is a single-channel thermal infrared image (white is cold; black is warm), which has been enhanced to highlight the cloud features. The image shows clouds in long semi-circular arcs. The series of wave-like cloud formations appear to be spreading out from a point located on the Western Australian coast near longitude $114^{\circ} \mathrm{E}$, latitude $24.5^{\circ} \mathrm{S}$. Similar wave-like structures have been observed over Australia by Smith (1986) and Reeder and Christie (1998). These are generally described as 'glories' and take on the appearance of long, narrow lines of clouds often occurring in the morning over the Gulf of Carpentaria (Clarke 1972), but also in the evening in northwestern Australia (Smith 1986). The dynamics of the 'Morning Glory' are described in terms of an atmospheric hydraulic jump. The occurrence of these wave-like clouds in the early morning or evening is related to the maintenance of a stable waveguide layer.

Concentric circles can be drawn over the image (figure $2(b)$ ) to coincide very closely with the cloud formations. The projection used is Lambert's Conformal with two standard parallels, and concentric circles appear as ellipses when projected onto the Earth using this projection. These cloud arcs or 'rings' are reminiscent of the waves formed when a stone is dropped into a pond. 


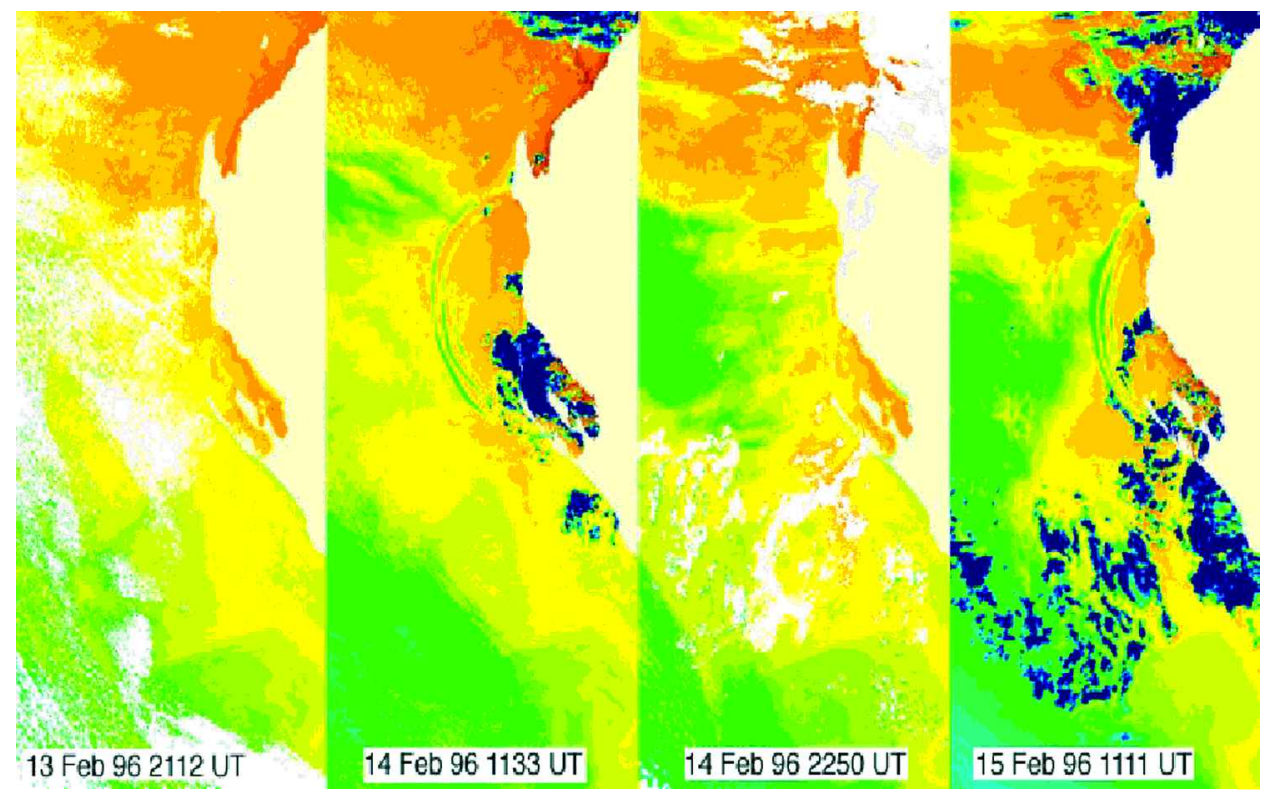

Figure 1. A sequence of four AVHRR-2 $11 \mu \mathrm{m}$ (channel 4) thermal infrared images showing unusual cloud formations off the Western Australian coast, in the evening ( $11 \mathrm{~h} 33 \mathrm{~min}$ UT or $19 \mathrm{~h} 33 \mathrm{~min}$ Local Time (UT $+8 \mathrm{~h}$ ) on 14 February, and $11 \mathrm{~h} 13 \mathrm{~min}$ UT or 19 h 13 min LT on 15 February).

Time-lapse MPEG movies have been made using hourly GMS-5 (the Japanese Geostationary Meteorological Satellite positioned at approximately $140^{\circ} \mathrm{E}$ ) infrared imagery (spatial resolution of $5 \mathrm{~km}$ ) for the two occasions studied. These can be viewed on the web at: http://www.dar.csiro.au/crc/. Analysis of these sequences of GMS-5 images suggests that the wavefronts are propagating away from the coast at a radial velocity of between 15 and $20 \mathrm{~m} \mathrm{~s}^{-1}$. The GMS-5 data also show that there was a great deal of convective activity in the area, as evidenced from the cloudiness of the imagery (also noticeable in the AVHRR image shown in figure 2). The AVHRR-2, GMS-5 and ancillary meteorological data allow some features of the concentric ring clouds (CRCs) to be determined:

- Cloud top temperature of the rings is about $18-20^{\circ} \mathrm{C}$. Examination of $12 \mu \mathrm{m}$ temperatures for the same images reveals that they are 0.2 to $0.5^{\circ} \mathrm{C}$ smaller than the $11 \mu \mathrm{m}$ temperatures. This implies that they are boundary layer clouds, probably capped by the maritime inversion 1.5 to $2.0 \mathrm{~km}$ high. Radiosonde data indicate that the air temperature at $2 \mathrm{~km}$ is about $20^{\circ} \mathrm{C}$.

- Distance between wave crests is about $15-20 \mathrm{~km}$. There is an indication of a change in wavelength $(\lambda)$ on the images with wavelength increasing with distance from the centre of the disturbance $(\lambda \approx 30 \mathrm{~km}$ at $\approx 300 \mathrm{~km}$ from the coast).

- The clouds have been noticed on only a few images and are most pronounced in the evening and nighttime data.

- The apparent centres of the disturbances on each of the AVHRR images shown are: 

- The synoptic weather pattern indicates light easterly flow at the surface with a coastal trough (the West coast low) forming.

- The CRC radial propagation speed is $15-20 \mathrm{~m} \mathrm{~s}^{-1}$.

\section{A hypothesis}

We do not know the precise origin or cause for these unusual cloud structures but the weight of evidence suggests that they may be formed by the cold outflow from a thunderstorm. We postulate that as the cold outflow from the storm enters the warm marine boundary layer, a solitary wave (or perhaps a sequence of solitary waves) is set in motion. The circular wavefront spreads out, apparently from a central point, away from the coast and towards the open ocean. A similar wavefront is not observed on the landward side of the (hypothesised) thunderstorm outflow, and this may be due to the difference in boundary layer structure over the land versus the ocean and to the fact that the low level winds are from the east.

GMS-5 $11 \mu \mathrm{m}$ 'brightness temperature' images obtained on 14 February, indicate that the coldest clouds (cloud-top temperatures $\approx-55^{\circ} \mathrm{C}$ ) occur at around $08 \mathrm{~h} 30 \mathrm{~min}$ UT. By $09 \mathrm{~h} 30 \mathrm{~min}$ UT the cloud-tops in the vicinity of the disturbance are all warmer than $-30^{\circ} \mathrm{C}$. These observations suggest that between $08 \mathrm{~h} 30 \mathrm{~min}$ UT and $09 \mathrm{~h} 30 \mathrm{~min}$ UT ( $16 \mathrm{~h} 30 \mathrm{~min}$ LT and $17 \mathrm{~h} 30 \mathrm{~min}$ LT) the convective build-up had ceased. A similar sequence of events occurred on the following day. The apparent centre of disturbance is located further inland, but still close to the thunderstorm activity. The storms appear to dissipate at around the same time as on the previous day.

These data support the contention that the CRCs occurred in the presence of thunderstorm activity and suggest that the outflows from the thunderstorms may have played a role in their generation.

The propagation centre of these clouds appears to be close to a large ephemeral salt lake-Lake MacLeod. Vigourous storm activity and a tropical cyclone brought large amounts of rain to the region during November 1995 to January 1996 and the lake received unsually large amounts of rainfall. The rainfall distribution over Western Australia for the period November 1995 to January 1996 suggests that above average rainfall was recorded for the region around Lake MacLeod. Such high amounts of rainfall would undoubtedly have caused an inflow to Lake MacLeod and Landsat satellite imagery of the lake confirms that standing water was evident in February. We speculate that the lake may have played a role in supplying latent heat energy and moisture for generating thunderstorms in the region.

\section{Wave propagation: model and analysis}

As noted above, the development of thunderstorms above the region near Lake MacLeod can cause low-level outflows of dense, relatively cold air. These can act as a source for gravity wave disturbances in an atmospheric wave guide. In summer, the atmosphere over the ocean to the west of Australia typically contains an inversion layer at a depth of about $2 \mathrm{~km}$ (Boers and Prata 1996). However, when there are prevailing easterlies, the temperature and dew point profiles close to the coastline (within, say, $200 \mathrm{~km}$ ) are significantly different from those over the ocean further west.

Specifically, the mid-tropospheric air is dry, having travelled over the Australian continent, and there is a moist, relatively dense surface layer with a depth of several hundred metres. Radiosonde observations from Learmonth $(\approx 200 \mathrm{~km}$ to the north) on the 13, 14 and 15 February 1996, which sample air affected by the sea breeze, 
indicate that on the days of the satellite observations, this surface layer is close to saturation. Winds in the region were relatively weak.

Hence we may assume that the lower troposphere over the ocean to the west of the continent on these days at latitudes $22^{\circ} \mathrm{S}$ to $26^{\circ} \mathrm{S}$ consists of a moist adiabatic lower layer that is near saturation, surmounted by a deep, much dryer adiabatic layer with larger potential temperature. For wave propagation purposes we represent this situation by a model consisting of two incompressible layers at rest and of total depth $D$ (the scale height of the troposphere). The lower layer has a thickness $d_{1}$ and density $\rho+\Delta \rho$, and the upper layer thickness $D-d_{1}$ and density $\rho$. The speed of linear waves $c_{0}$ on the interface between these two layers is given by,

$$
c_{0}=\sqrt{\frac{g \Delta \rho}{\rho} d_{s}}
$$

where $d_{s}=r(1-r) D$, and $r=d_{1} / D$. However, it is now common experience that waves propagating in such systems are not linear unless their amplitudes are quite small. Disturbances that have been generated to amplitudes that are observable by satellite sensors, whether in the atmosphere or ocean, are generally non-linear, and are governed by equations of the Korteweg-de Vries (KdV) type that include the effects of non-linear steepening and wave dispersion. For this two-layer system, the appropriate equation is the extended $\mathrm{KdV}$ equation $(\mathrm{eKdV})$. If the vertical displacement of the interface between the two layers is denoted by $\eta$, this eKdV equation has the form (Baines 1995),

$$
\eta_{t}+c_{0} \eta_{x}+\frac{3 c_{0}}{2 d_{s}}\left[(1-2 r) \eta-2 \frac{\left[r^{3}+(1-r)^{3}\right]}{d_{s}} \eta^{2}\right] \eta_{x}+\frac{c_{0} d_{s}^{2}}{6 r(1-r)} \eta_{x x x}=0
$$

This equation has the solitary wave solution

$$
\eta=\frac{a}{\cosh ^{2} \theta-\mu \sinh ^{2} \theta}, \quad \theta=\left[x-c_{0}\left(1+\frac{2\left(d_{s} / l\right)^{2}}{3 r(1-r)}\right) t\right] / l+\theta_{0}
$$

where $\theta_{0}$ is an arbitrary phase, $\mu$ is a parameter in the range $0<\mu<1$, and the wave amplitude $a$ and half length $l$ are given by

$$
a=\left(\frac{\mu}{1+\mu}\right)\left(\frac{1-2 r}{1-3 r+3 r^{2}}\right) d_{s}, \quad l^{2}=D^{2} \frac{4\left(1+\mu^{2}\right)}{3 \mu} \frac{r(1-r)\left(1-3 r+3 r^{2}\right)}{(1-2 r)^{2}}
$$

The wave speeds $c$ are given by

$$
c=c_{0}\left[1+\frac{1}{2}(1-2 r) \frac{a}{d_{s}}-\frac{1}{2}\left(1-3 r+3 r^{2}\right)\left(\frac{a}{d_{s}}\right)^{2}\right]
$$

Note that these are waves of elevation of the lower layer, in which the layer thickness $d_{1}$ increases monotonically to $d_{1}+a$, and then back to $d_{1}$. These waves are isolated entities, but these equations give an approximate description of them as individual members of a successive train of such waves.

Equations (2)-(5) relate to wave propagation in one dimension, whereas the observed waves are spreading out in two dimensions from a localised source. However, at sufficient distances from the source where the radius of curvature of the wave crests is much greater than the wavelength, the one-dimensional propagation equations may be used as a local approximation. The wave parameters (amplitude, wavelength) may 
then be expected to change as the distance from the source increases. From observation s of successive images, the wave propagation speeds at a distance of $\approx 100 \mathrm{~km}$ from the source are about $18 \mathrm{~m} \mathrm{~s}^{-1}$, and the wavelengths (distance between crests) are about $21 \mathrm{~km}$. The radiosonde at Learmonth $\left(22.24^{\circ} \mathrm{S}, 114.09^{\circ} \mathrm{E}\right)$ indicates a mean layer temperature $(0-2 \mathrm{~km})$ of $\approx 28^{\circ} \mathrm{C}$ at $22 \mathrm{~h} 00$ min UT on 14 and 15 February 1996. Using (1) with $D=8 \mathrm{~km}$ (the atmospheric scale height) and $\Delta \rho / \rho=\Delta \theta / \theta$, where $\theta$ is the potential temperature of the lower layer in the atmosphere and $\Delta \theta$ is the change in potential temperature at the top of this layer, and taking $c_{0}=18 \mathrm{~m} \mathrm{~s}^{-1}, \theta \approx 300 \mathrm{~K}$, we obtain $r(1-r) \Delta \theta=1.24 \mathrm{~K}$. To satisfy this equation with values of $r$ and $\Delta \theta$ that are realistic, we take $r=0.19$ and $\Delta \theta=8 \mathrm{~K}$. This gives a lower layer thickness of $1500 \mathrm{~m}$. Substantial departure from these conditions would involve values of $d_{1}$ or $\Delta \theta$ that are unrealistically large, and we assume these values in what follows.

Equating $2 l$ with the observed wavelength of $21 \mathrm{~km}$ in (4) then gives $\mu=0.268$ and $a=300 \mathrm{~km}$. With the passage of a wave, therefore, the upper part of the layer will rise from $1500 \mathrm{~m}$ to $1800 \mathrm{~m}$, resulting in a fall in air temperature of about $2.5 \mathrm{~K}$. If this lower layer is close to saturation, this elevation causes condensation and cloud formation, thereby rendering the wave visible. At a larger radial distance of $400 \mathrm{~km}$ from the source the wavelength is observed to be $30 \mathrm{~km}$, and the equations then give $\mu=0.098$ and $a \approx 130 \mathrm{~m}$, consistent with decreasing amplitude because of lateral spreading and dissipation.

The propagation conditions inland from the coast are quite different from those over the sea. The sea breeze on the previous day is observed to establish a dense moist lower layer of about $1500 \mathrm{~m}$ near the coast, but as it moves inland this layer will be eroded during the day by surface heating, and the conditions supporting wave propagation will rapidly disappear. No waves were observed by satellite over the land.

These propagation conditions should be quite common in this region, particularly during the summer. What is unusual is the generation region, dependent on the source of latent heat from the tropical cyclone of two months previously.

\section{Conclusion}

The concentric ring clouds described in this Letter appear to be a rare and dynamically interesting phemonenon. Although other explanations may be possible, their origin, cause and dynamics appear to be associated with summertime convective activity near a coastal environment, the cold outflow from a mature thundercloud, and the subsequent initiation of a solitary wave or sequence of solitary waves that propagate in a waveguide, presumably formed in part by the maritime boundary layer inversion.

\section{References}

Baines, P. G., 1995, Topographic Effects in Stratified Flows (Cambridge: Cambridge University Press).

Boers, R. E., and Prata, A. J., 1996, Thermodynamic structure of the maritime troposphere around the Australian continent. International Journal of Climatology, 16, 633-650.

Clarke, R. H., 1972, The morning glory: An atmospheric hydraulic jump. Journal of Applied Meteorology, 11, 304-311.

Reeder, M. J., and Christie, D. R., 1998, Four large-amplitude wave families observed simultaneously over northern Queensland, Australia. Weather, 53, 134-140.

Smith, R. K., 1986, 'Evening Glory' wave-cloud lines in northwestern Australia. Australian Meteorological Magazine, 34, 27-33. 